University of Wollongong

Research Online

Faculty of Engineering and Information

Faculty of Engineering and Information

Sciences - Papers: Part A

Sciences

$1-1-2014$

Electrochemistry and structure of the cobalt-free $\mathrm{Li} 1+x \mathrm{MO} 2(\mathrm{M}=\mathrm{Li}, \mathrm{Ni}, \mathrm{Mn}$, $\mathrm{Fe}$ ) composite cathode

Wei Kong Pang

University of Wollongong, wkpang@uow.edu.au

Sujith Kalluri

University of Wollongong, sk027@uowmail.edu.au

Vanessa Peterson

Australian Nuclear Science and Technology Organisation, vep@ansto.gov.au

SX. Dou

University of Wollongong, shi@uow.edu.au

Zaiping Guo

University of Wollongong, zguo@uow.edu.au

Follow this and additional works at: https://ro.uow.edu.au/eispapers

Part of the Engineering Commons, and the Science and Technology Studies Commons

Research Online is the open access institutional repository for the University of Wollongong. For further information contact the UOW Library: research-pubs@uow.edu.au 


\title{
Electrochemistry and structure of the cobalt-free Li1+xMO2 (M = Li, Ni, Mn, Fe) composite cathode
}

\begin{abstract}
The development of cathode materials with high capacity and cycle stability is essential to emerging electric-vehicle technologies, however, of serious environmental concern is that materials with these properties developed so far contain the toxic and expensive Co. We report here the Li-rich, Co-free $\mathrm{Li} 1+x M O 2(\mathrm{M}=\mathrm{Li}, \mathrm{Ni}, \mathrm{Mn}, \mathrm{Fe})$ composite cathode material, prepared via a template-free, one-step wetchemical method followed by conventional annealing in an oxygen atmosphere. The cathode has an unprecedented level of cation mixing, where the electrochemically-active component contains four elements at the transition-metal (3a) site and $20 \% \mathrm{Ni}$ at the active Li site (3b). We find $\mathrm{Ni2}+/ \mathrm{Ni} 3+/ \mathrm{Ni} 4+$ to be the active redox-center of the cathode with lithiation/delithiation occurring via a solid-solution reaction where the lattice responds approximately linearly with cycling, differing to that observed for iso-structural commercial cathodes with a lower level of cation mixing. The composite cathode has $\sim 75 \%$ active material and delivers an initial discharge-capacity of $\sim 103 \mathrm{~mA} \mathrm{~h} \mathrm{g-1}$ with a reasonable capacity retention of $\sim 84.4 \%$ after 100 cycles. Notably, the electrochemically-active component possesses a capacity of $\sim 139 \mathrm{~mA} \mathrm{~h} \mathrm{g-1,} \mathrm{approaching} \mathrm{that} \mathrm{of} \mathrm{the} \mathrm{commercialized} \mathrm{LiCoO2} \mathrm{and} \mathrm{Li(Ni1/3Mn1/3Co1/3)O2} \mathrm{materials.}$ Importantly, our operando neutron powder-diffraction results suggest excellent structural stability of this active component, which exhibits $\sim 80 \%$ less change in its stacking-axis than for LiCoO2 with approximately the same capacity, a characteristic that may be exploited to enhance significantly the capacity retention of this and similar materials.

\section{Disciplines}

Engineering | Science and Technology Studies

\section{Publication Details}

Pang, W., Kalluri, S., Peterson, V. K., Dou, S. Xue. \& Guo, Z. (2014). Electrochemistry and structure of the cobalt-free Li1+xMO2 (M = Li, Ni, Mn, Fe) composite cathode. Physical Chemistry Chemical Physics, 16 (46), 25377-25385.
\end{abstract}




\title{
Electrochemistry and Structure of the Cobalt-free $\mathrm{Li}_{1+x} \mathrm{MO}_{2}(M=\mathrm{Li}, \mathrm{Ni}, \mathrm{Mn}, \mathrm{Fe})$ Composite Cathode
}

\author{
Wei Kong Pang, ${ }^{\text {ab }}$ Sujith Kalluri, ${ }^{\text {b }}$ Vanessa K. Peterson, ${ }^{* a}$ Shi Xue Dou, ${ }^{\text {b }}$ and \\ Zaiping Guo*b
}

\begin{abstract}
The development of cathode materials with high capacity and cycle stability is essential to emerging electric-vehicle technologies, however, of serious environmental concern is that materials with these properties developed so far contain the toxic and expensive Co. We report here the Li-rich, Co-free $\mathrm{Li}_{1+x} M \mathrm{O}_{2}(M=\mathrm{Li}, \mathrm{Ni}, \mathrm{Mn}, \mathrm{Fe})$ composite cathode material, prepared via a template-free, one-step wetchemical method followed by conventional annealing in an oxygen atmosphere. The cathode has an unprecedented level of cation mixing, where the electrochemically-active component contains four elements at the transition-metal $(3 a)$ site and $20 \% \mathrm{Ni}$ at the active $\mathrm{Li}$ site $(3 b)$. We find $\mathrm{Ni}^{2+} / \mathrm{Ni}^{3+} / \mathrm{Ni}^{4+}$ to be the active redox-center of the cathode with lithiation/delithiation occurring via a solid-solution reaction where the lattice responds approximately linearly with cycling, differing to that observed for iso-structural commercial cathodes with a lower level of cation mixing. The composite cathode has $\sim 75 \%$ active material and delivers an initial discharge-capacity of $\sim 103 \mathrm{mAh} . \mathrm{g}^{-1}$ with a reasonable capacity retention of $\sim 84.4 \%$ after 100 cycles. Notably, the electrochemically-active component possesses a capacity of $139 \mathrm{mAh} . \mathrm{g}^{-1}$, approaching that of the commercialized $\mathrm{LiCoO}_{2}$ and $\mathrm{Li}\left(\mathrm{Ni}_{1 / 3} \mathrm{Mn}_{1 / 3} \mathrm{Co}_{1 / 3}\right) \mathrm{O}_{2}$ materials. Importantly, our operando neutron powder-diffraction results suggest excellent structural stability of this active component, which exhibits $\sim 80 \%$ less change in its stacking-axis than for $\mathrm{LiCoO}_{2}$ with approximately the same capacity, a characteristic that may be exploited to enhance significantly the capacity retention of this and similar materials.
\end{abstract}

\section{Introduction}

Since the introduction of the first commercial Li-ion battery containing $\mathrm{LiCoO}_{2}$ as the cathode and graphite as the anode by Sony in $1991,{ }^{1}$ the Li-ion battery has become the preferred choice for powering portable electronic-devices. Despite a theoretical capacity of $274 \mathrm{mAh} . \mathrm{g}^{-1}$, the practical capacity of $\mathrm{LiCoO}_{2}$ is restricted to $140 \mathrm{mAh} \cdot \mathrm{g}^{-1}$ as a consequence of structural stability issues, where only half of the $\mathrm{Li}$ can be removed before the structure decomposes into $\mathrm{CoO}_{2}{ }^{2-4}$ Moreover, $\mathrm{LiCoO}_{2}$ has a relatively-poor rate capability and contains toxic and expensive Co. The world Co price is currently determined by Li-ion battery demands, and the present and significant research effort to find alternative, Cofree cathodes that are environmentally-friendly with good electrochemical performance is of great global importance. $\mathrm{Ni}$ and $\mathrm{Mn}$ have been used to replace Co to form the alternative cathode materials $\mathrm{LiNiO}_{2}{ }^{5}$ and $\mathrm{LiMnO}_{2}{ }^{6}$, ${ }^{7}$, respectively. Although Co-free, these materials are difficult to prepare and thermally unstable at their charged state. Importantly, to date Co-free cathodes have suffered significantly from poor structural stability. For example, the $\mathrm{Li}_{2} \mathrm{MnO}_{3}$ cathode and its derivatives exhibit severe capacity-decay, despite an initial discharge-capacity exceeding $200 \mathrm{mAh} \cdot \mathrm{g}^{-1}$ after charging beyond 4.6 V, ${ }^{8-10}$ with Jahn-Teller distortion of $\mathrm{Mn}^{3+}$ contributing significantly to instability on cycling. ${ }^{6,11-13}$

The cycling performance and stability of a battery is of utmost importance and in commercial use capacity is sacrificed to achieve this. ${ }^{14,15}$ Cycle stability and good battery-lifetime are achieved industrially through constraints on the cycle depth, ${ }^{14}$, ${ }^{15}$ ensuring structural stability at the expense of capacity, where constraint of the discharge to $40 \%$ is commonplace. Whilst stabilizing the bulk of the cathode, this approach does not prevent cathode destabilization as a result of local clusters of fully-transformed material, with the macroscopic lithiation mechanism a significant influence on this. One method to overcome this is to incorporate redox-inert transition-metal centers into the material, which stabilize the structure during charge-discharge cycling. The mixed transition-metal $\mathrm{Li}\left(\mathrm{Ni}_{1 / 3} \mathrm{Mn}_{1 / 3} \mathrm{Co}_{1 / 3}\right) \mathrm{O}_{2}$, iso-structural to $\mathrm{LiCoO}_{2}$ and reported by Yabuuchi and Ohzuku, is now commercially-used. ${ }^{16}$ Although $\mathrm{Mn}$ and $\mathrm{Co}$ are electrochemically inert in the active voltage range of $\mathrm{Li}\left(\mathrm{Ni}_{1 / 3} \mathrm{Mn}_{1 / 3} \mathrm{Co}_{1 / 3}\right) \mathrm{O}_{2}$, the valence of $\mathrm{Ni}$ changes from $2+$ to $4+$ and effectively doubles the capacity, with the reversible capacity of this cathode in excess of $200 \mathrm{mAh} \cdot \mathrm{g}^{-1}{ }^{16}$, 17 The inert redox centers in $\mathrm{Li}\left(\mathrm{Ni}_{1 / 3} \mathrm{Mn}_{1 / 3} \mathrm{Co}_{1 / 3}\right) \mathrm{O}_{2}$ make this material more stable than $\mathrm{LiCoO}_{2},{ }^{18}$ although the presence of Co and the relatively-poor rate performance of $\mathrm{Li}\left(\mathrm{Ni}_{1 / 3} \mathrm{Mn}_{1 / 3} \mathrm{Co}_{1 / 3}\right) \mathrm{O}_{2}$ remain problems. Although mixed transition-metal oxides with a further reduced amount of $\mathrm{Co}$ have been synthesized, such as $\mathrm{LiMn}_{0.4} \mathrm{Ni}_{0.4} \mathrm{Co}_{0.2} \mathrm{O}_{2}$ and $\mathrm{LiMn}_{0.42} \mathrm{Ni}_{0.42} \mathrm{Co}_{0.16} \mathrm{O}_{2},{ }^{19-21}$ expensive and toxic Co remains. More recently, the novel, eco-friendly, and Co-free $\mathrm{Li}\left(\mathrm{Ni}_{1 / 3} \mathrm{Mn}_{1 / 3} \mathrm{Fe}_{1 / 3}\right) \mathrm{O}_{2}$ was reported, with a theoretical capacity of $281 \mathrm{mAh} \cdot \mathrm{g}^{-1}$, exceptional rate-performance, and the reasonably-high practical discharge-capacity of $170 \mathrm{mAh} \cdot \mathrm{g}^{-1}$ in the presence of a conducting polyaniline network. The evolution of metal-oxide cathodes from the first $\mathrm{LiCoO}_{2}$ 
material to $\mathrm{Li}\left(\mathrm{Ni}_{1 / 3} \mathrm{Mn}_{1 / 3} \mathrm{Co}_{1 / 3}\right) \mathrm{O}_{2}$ and $\mathrm{Li}\left(\mathrm{Ni}_{1 / 3} \mathrm{Mn}_{1 / 3} \mathrm{Fe}_{1 / 3}\right) \mathrm{O}_{2}$ materials, stands testament to the importance of the serious environmental concerns in the interest of the application of cathodes for low or zero-emission transportation such as to power hybrid-electric and electric vehicles, where both high capacity, cycle stability, and good rate-performance are required.

An alternative to mixed transition-metal oxides as highly stable cathode materials is the use of an additional and inactive phase, such as the superlattice-structured $\mathrm{Li}_{2} \mathrm{MnO}_{3} \cdot{ }^{22-24}$ Here the cathode functions as a composite, where the $\mathrm{Li}_{2} \mathrm{MnO}_{3}$ offers additional stability during high-voltage charge. ${ }^{22-25}$ Following this theory, new cathodes with excess Li are being created, such as the $\mathrm{Li}_{2} \mathrm{MnO}_{3} \cdot \mathrm{LiNi}_{0.5} \mathrm{Mn}_{0.5} \mathrm{O}_{2}$ composite, with the aim of improving both cycling stability and capacity for future Li-ion battery applications. ${ }^{26-28}$

In order to direct the development of cathodes with improved performance, the atomic-level structural response of $\mathrm{LiCoO}_{2}{ }^{2-4}$ and $\mathrm{Li}\left(\mathrm{Ni}_{1 / 3} \mathrm{Mn}_{1 / 3} \mathrm{Co}_{1 / 3}\right) \mathrm{O}_{2}{ }^{29}$ during lithiation and delithiation have been studied. Delithiation in $\mathrm{LiCoO}_{2}$ is reported to proceed through a solid-solution reaction to form $\mathrm{Li}_{x} \mathrm{CoO}_{2}(x=$ $\sim 0.5$ with capacity $\sim 140 \mathrm{mAh} \cdot \mathrm{g}^{-1}$ ), with further Li extraction inducing the formation of $\mathrm{CoO}_{2}$ via a two-phase reaction. ${ }^{2-4}$ During the solid-solution reaction, the lattice parameter $c$ first increases, before decreasing at the charged state. This reversible non-linear behaviour is also observed in the iso-structural $\mathrm{Li}\left(\mathrm{Ni}_{1 / 3} \mathrm{Mn}_{1 / 3} \mathrm{Co}_{1 / 3}\right) \mathrm{O}_{2}$ cathode. $^{18,29}$ Under further delithiation, $\mathrm{Li}\left(\mathrm{Ni}_{1 / 3} \mathrm{Mn}_{1 / 3} \mathrm{Co}_{1 / 3}\right) \mathrm{O}_{2}$ decomposes via a two-phase reaction, forming the $\mathrm{Li}_{0.04}\left(\mathrm{Ni}_{1 / 3} \mathrm{Mn}_{1 / 3} \mathrm{Co}_{1 / 3}\right) \mathrm{O}_{2}$ material with space group $P \overline{3} m 1{ }^{18}$ The generally-accepted explanation for the non-linear behaviour of the lattice of these layered cathodes is that during initial charging (delithiation) electrostatic repulsion of the oxygen-containing layers occurs, with the decreasing average charge of the $\mathrm{O}$-ions at the high-charge state reducing the repulsion between the layers and consequently, the inter-layer distance. Although it is generally accepted that the capacity of $\mathrm{Li}\left(\mathrm{Ni}_{1 / 3} \mathrm{Mn}_{1 / 3} \mathrm{Co}_{1 / 3}\right) \mathrm{O}_{2}$ arises from the $\mathrm{Ni}^{2+} / \mathrm{Ni}^{3+} / \mathrm{Ni}^{4+}$ redox centers within the 3-4 $\mathrm{V}$ operating window, the contribution of the $\mathrm{Mn}^{3+} / \mathrm{Mn}^{4+}$ and $\mathrm{Co}^{3+} / \mathrm{Co}^{4+}$ redox couples to this capacity is also reported. ${ }^{30-33}$

In this work, we report a Li-rich $\mathrm{Li}_{1+x} M \mathrm{O}_{2}\left(x \mathrm{Li}_{2} M \mathrm{O}_{3} \bullet(1-\right.$ $x)\left(\mathrm{Li}_{5 / 6} \mathrm{Ni}_{1 / 6}\right)\left(\mathrm{Li}_{1 / 6} \mathrm{Ni}_{1 / 6} \mathrm{Mn}_{1 / 3} \mathrm{Co}_{1 / 3}\right) \mathrm{O}_{2}$ composite material, $M=$ $\mathrm{Li}, \mathrm{Ni}, \mathrm{Mn}, \mathrm{Fe})$ that is Co free. We study its electrochemical performance and function, determining the phase evolution of the active phase $\left(\mathrm{Li}_{5 / 6} \mathrm{Ni}_{1 / 6}\right)\left(\mathrm{Li}_{1 / 6} \mathrm{Ni}_{1 / 6} \mathrm{Mn}_{1 / 3} \mathrm{Co}_{1 / 3}\right) \mathrm{O}_{2}$ using operando neutron powder diffraction (NPD). We examine the lithiation/delithiation mechanism of the active phase within a whole battery alongside the typical two-phase transitions of the graphite anode during galvanostatic charge and discharge within the $2.0-4.5 \mathrm{~V}$ window (vs. graphite), noting that the Lirich $\mathrm{Li}_{2} \mathrm{MO}_{3}$ component ( $25 \mathrm{wt} . \%$ ) is electrochemically inert. By examining the oxygen positional-parameter during cycling, we establish the origin of the capacity of the $\left(\mathrm{Li}_{5 / 6} \mathrm{Ni}_{1 / 6}\right)\left(\mathrm{Li}_{1 / 6} \mathrm{Ni}_{1 / 6} \mathrm{Mn}_{1 / 3} \mathrm{Co}_{1 / 3}\right) \mathrm{O}_{2}$ phase. Our structural study is coupled with our examination of the cathode's performance characteristics to establish the structure-function relation of this novel cathode material.

\section{Experimental}

The cathode powder was synthesized using a precursor solution prepared by dissolving stoichiometric amounts of $\mathrm{LiNO}_{3}$, $\mathrm{Mn}\left(\mathrm{CH}_{3} \mathrm{COO}\right)_{2}, \mathrm{Ni}\left(\mathrm{CH}_{3} \mathrm{COO}\right)_{2}$, and $\mathrm{Fe}\left(\mathrm{CH}_{3} \mathrm{COO}\right)_{2}$ (SigmaAldrich) in an adequate amount of ethanol and N,N-dimethyl formamide. $20 \%$ excess $\mathrm{LiNO}_{3}$ was added to form $\mathrm{Li}_{1+x}\left(\mathrm{Mn}_{1 / 3} \mathrm{Ni}_{1 / 3} \mathrm{Fe}_{1 / 3}\right) \mathrm{O}_{2}$. After stirring for $1.5 \mathrm{hr}$., $10 \mathrm{wt} . \%$ of polyvinylpyrrolidone $\left(1,300,000\right.$ g. $\mathrm{mol}^{-1}$, Sigma-Aldrich) was added to the resultant solution. After overnight stirring, the precursor was dried at $100{ }^{\circ} \mathrm{C}$ for $24 \mathrm{hr}$. to evaporate solvents and then calcined at $900{ }^{\circ} \mathrm{C}$ for $2 \mathrm{hr}$. with a heating rate of 300 ${ }^{\circ} \mathrm{C} \mathrm{h}^{-1}$ in flowing oxygen to obtain the cathode powder.

The phase composition and crystallographic structure of the asprepared cathode powder was obtained using XRPD with a GBC mini-material analyzer (U.S.A) with $\mathrm{CuK \alpha} \alpha$ radiation. Morphological and particle size studies were performed using SEM with a JEOL JSM-7500 (Japan). High-resolution NPD data were collected using ECHIDNA, the high-resolution neutron powder diffractometer at the Open Pool Australian Light-water (OPAL) research reactor at the Australian Nuclear Science and Technology Organisation (ANSTO). ${ }^{34}$ The neutron beam wavelength was 1.6238(3) $\AA$, determined using the $\mathrm{La}^{11} \mathrm{~B}_{6}$ NIST standard reference material $660 \mathrm{~b}$. The NPD data were obtained in the $2 \theta$ angular range 4 to $164^{\circ}$ with a step size of $0.125^{\circ}$. Fullprof with visualization in Winplot $R^{35,36}$ was employed to perform Rietveld analysis of the obtained XRPD and high-resolution NPD data. The parameters including background coefficients, zero-shift, peak shape parameters, lattice parameters, the $\mathrm{O}$ positional parameter, and isotropic atomic displacement parameters are optimized.

A specially designed pouch-type battery was used in the collection of operando NPD data from the cathode. The cathode was prepared by casting a slurry of the cathode powder (80 wt.\%), carbon black (Super P, TIMCAL, Switzerland) (10 wt.\%), and polyvinylidene difluoride (PVDF) binder (10 wt.\%) onto Al foil. Commercial double-side coated MCMB anodes were used as the counter electrode. The electrodes were cut into $1.5 \times 7 \mathrm{~cm}$ strips with a coated area of $1.5 \times 4.5 \mathrm{~cm}$. Immobilon-P PVDF membrane (Millipore) was used as a separator due to its lower $\mathrm{H}$ content relative to the conventionally-used Celgard membrane, where the strong incoherent neutron-scattering of $\mathrm{H}$ is detrimental to the NPD signal. The battery was prepared by stacking 16 anode/separator/cathode assemblies with a parallel connection. The stack was placed in an Ar-filled glove box for $24 \mathrm{~h}$ and then wrapped in a polypropylene-coated Al foil to form a pouch. The dimension of the prepared cell was $3 \mathrm{~cm}$ wide (including the sealing junction of the Al pouch), $10 \mathrm{~cm}$ long (including electrode handles), and $\sim 0.8 \mathrm{~cm}$ thick. Prior to the operando NPD experiment, deuterated electrolyte solution (1 M lithium hexafluorophosphate (99.99\%, Sigma-Aldrich) in a $1: 1$ volume ratio of deuterated dimethyl carbonate (DMC) $(99.5 \%$, 
Novachem) to deuterated ethylene carbonate (EC) $(98 \%$, Novachem) was injected into the pouch which was heat-sealed under Ar. After 1-day of wetting, the battery was used in the operando NPD experiment. During the operando NPD experiment, the battery was cycled galvanostatically using a potentiostat/galvanostat (Autolab PG302N) at a current of 3 $\mathrm{mA}$ for the first two cycles and $4.5 \mathrm{~mA}$ for the third cycle between 2.0 and $4.5 \mathrm{~V}$ (vs. MCMB). Operando NPD data of the battery were collected using WOMBAT, ${ }^{37}$ the highintensity neutron powder diffractometer at the OPAL research reactor at ANSTO. WOMBAT features an area detector that continuously covers $120^{\circ}$ in $2 \theta$ and has a relatively intense neutron beam, allowing the rapid collection of data. A neutron beam with a wavelength of 2.4174(1) $\AA$ was used, determined using the $\mathrm{La}^{11} \mathrm{~B}_{6}$ NIST Standard Reference Material 660b. The diffractograms were obtained with an exposure time of 5 minutes per pattern in the angular range $16.1-136.9^{\circ}$ in $2 \theta$ during charge-discharge cycling. The NPD data of the uncycled battery was analyzed using Fullprof with visualization in WinplotR. ${ }^{35,36}$ The refinements were performed using data in the range $35-120^{\circ}$ in $2 \theta$. Single-peak fitting of cathode 018 reflections were performed using the Large Array Manipulation Program (LAMP). ${ }^{38}$ Origin ver. 8.1 (OriginLab, Northampton, MA) was also used for fitting overlapping lithiated graphite reflections.

The electrochemical properties of the cathode were measured using CR2032 coin-type half-cell with this cathode assembled in an Ar-filled glove box (MBraun, Germany). The electrode slurry was prepared by milling the cathode powder with carbon black (Super P, TIMCAL, Switzerland) and PVDF in a ratio 80:10:10 with N-methyl-2-pyrrolidone (Sigma-Aldrich) in a planetary mixer (Kurabo Mazerustar, Japan). Resultant slurries were coated onto an Al current collector using traditional doctor blading before being dried in vacuum at $120{ }^{\circ} \mathrm{C}$ overnight. The coin-cells were assembled using Li foil (SigmaAldrich, USA) as the counter electrode, polypropylene film as a separator, and $1 \mathrm{M} \mathrm{LiPF} 6$ in conventional ethylene carbonate (EC): di-ethylene carbonate (DEC) (1:1 vol.) as electrolyte. Galvanostatic cycling at various rates were performed using battery analyser (Land, China). The specific capacity (mAh.g ${ }^{-1}$ ) that we measure is calculated for the entire composite cathode, including the $\mathrm{Li}_{2} M \mathrm{O}_{3}$ phase that is electrochemically inert within $2.0-4.5 \mathrm{~V}$ operating window.

\section{Results and discussion}

Rietveld refinement profiles using X-ray powder diffraction (XRPD) and high-resolution NPD data are shown along with scanning electron microscopy (SEM) images in Figure 1. XRPD data (Figure 1a) are modelled using a modified $\alpha$ $\mathrm{NaFeO}_{2}$ structure with the $R \overline{3} m$ space group. ${ }^{39,}$, 40 The $R \overline{3} m$ phase 104 reflection exhibits asymmetry and broadening that suggests a shoulder peak. Further investigation of this and other reflections unindexed by the $R \overline{3} m$ space-group were able to be indexed using a $C 2 / \mathrm{m}$ space-group, which we ascribe to a $\mathrm{Li}$ rich component such as $\mathrm{Li}_{2} M \mathrm{O}_{3}(M=\mathrm{Li}, \mathrm{Ni}, \mathrm{Mn}, \mathrm{Fe})$. The ratio of the $R \overline{3} m$ phase 003 and 104 reflection intensities is determined to be 2.20 , which is far from unity and indicates that the main phase is a layered structure with a high level of cation mixing, in which the $(003)$ plane is filled with metals including $\mathrm{Li}$ and the (104) plane is shared by all the elements in the material. We note that splitting of the 006 and 102 as well as the 018 and 110 reflections, characteristic for the $R \overline{3} m$ layered structure, is not clearly observed due to peak broadening that likely arises from the relatively-small particle size of $\sim 100 \mathrm{~nm}$ (Figure 1c) and the high level of cation mixing. ${ }^{39,40}$
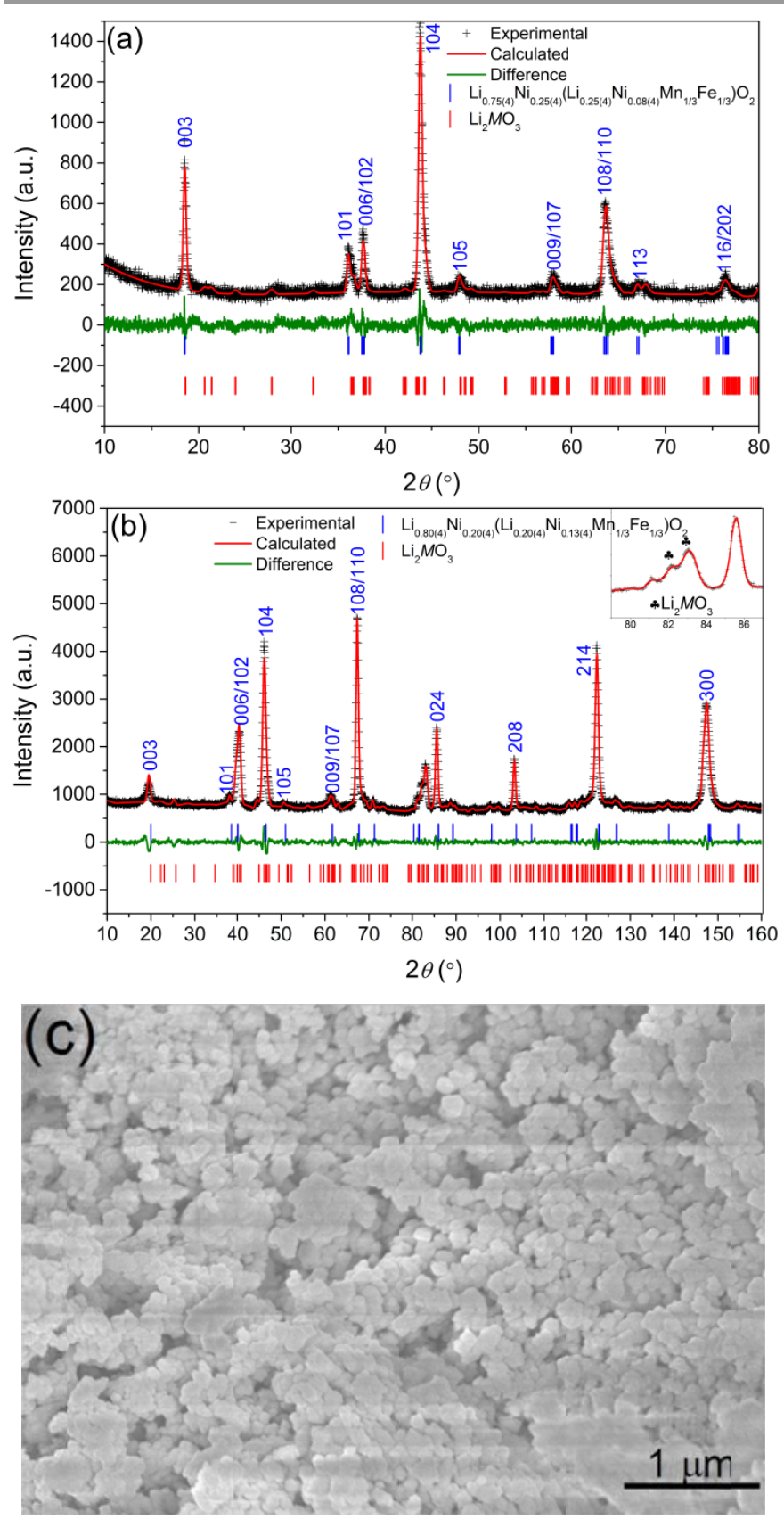

Figure 1. (a) Refinement plot using XRPD data of the as-synthesized cathode powder with goodness of fit $\left(\chi^{2}\right)=1.42$, weighted profile $\mathrm{R}$-factor $\left(\mathrm{R}_{\mathrm{wp}}\right)=27.9 \%$, Bragg R-factor $\left(\mathrm{R}_{\mathrm{B}}\right)=2.16 \%$ (LNMFO) and $3.9 \%\left(\mathrm{Li}_{2} \mathrm{MO}_{3}\right)(\mathrm{b})$ refinement plot using NPD data with $\chi^{2}=3.61, R_{w p}=19.9 \%$, Bragg-R factor $=12.6 \%$ (LNMFO) and $=$ $0.25 \%\left(\mathrm{Li}_{2} \mathrm{MO}_{3}\right)$, and (c) SEM image of the as-prepared cathode powder. 
The relatively-higher sensitivity of NPD to $\mathrm{Li}$ in this material compared to XRPD means that the $R \overline{3} m \quad 104$ and 018 reflections are stronger in the NPD than the XRPD data (Figure 1b) and that the $\mathrm{Li}_{2} M \mathrm{O}_{3}$ phase is more easily observed. Because of this, the final refined cathode-structure was obtained using the using NPD data. Whilst the structure of the second Li-rich $C 2 / m$ phase could not be modelled using the NPD data, a Le Bail refinement of this phase was included alongside a constrained Rietveld-refinement of the main $R \overline{3} m$ structure, allowing the crystallographic detail of the $R \overline{3} m$ phase to be extracted as shown in Table 1 and Figure 2. The lattice parameters of the $C 2 / \mathrm{m}$ phase were determined to be $a=$ 4.9381(1), $b=8.6386(4)$, and $c=4.9849(2) \AA$, with $\beta=$ $108.872^{\circ}$, which differ slightly to that reported for $\mathrm{Li}_{2} \mathrm{MnO}_{3}$ where $a=4.9292, b=8.5315$, and $c=5.0251 \AA$, with $\beta=$ $109.337^{\circ} .^{22}$ Importantly, the intensity of the $C 2 / m$ phase reflections in the NPD differ from that simulated for the reported $\mathrm{Li}_{2} \mathrm{MnO}_{3}$, likely as a result of the partial substitution of $\mathrm{Mn}$ by $\mathrm{Ni}$ and $\mathrm{Fe}$. The $R \overline{3} m$ phase is found to be $\left(\mathrm{Li}_{0.80(4)} \mathrm{Ni}_{0.20(4)}\right)\left(\mathrm{Li}_{0.20(4)} \mathrm{Ni}_{0.13(4)} \mathrm{Mn}_{0.33} \mathrm{Fe}_{0.33}\right) \mathrm{O}_{2}$ (LNMFO), in which $\mathrm{Li}$ atoms share the octahedral $3 b$ site with $\mathrm{Ni}$ atoms, these being sandwiched between layers of hybrid $\mathrm{Ni} / \mathrm{Mn} / \mathrm{FeO}_{6}$ octahedra. The hexagonal layered-structure of LNMFO is an O3-type, in good agreement with that reported for $\mathrm{Li}\left(\mathrm{Ni}_{1 / 3} \mathrm{Mn}_{1 / 3} \mathrm{Fe}_{1 / 3}\right) \mathrm{O}_{2},{ }^{39}, 40$ with the major difference being the high level of $\mathrm{Li} / \mathrm{Ni}$ cation mixing at both $3 a$ and $3 b$ sites (Figure 2 ). This cation mixing can complicate the electrochemical function of the cathode as the active Li intercalation layer ( $3 b$ site) contains inactive $\mathrm{Ni}$ which may lower capacity and block Li diffusion. ${ }^{30,41}$ Nevertheless, it is the inactive $\mathrm{Ni}$ in this layer which is expected to increase structural stability and the subsequent cycling performance.

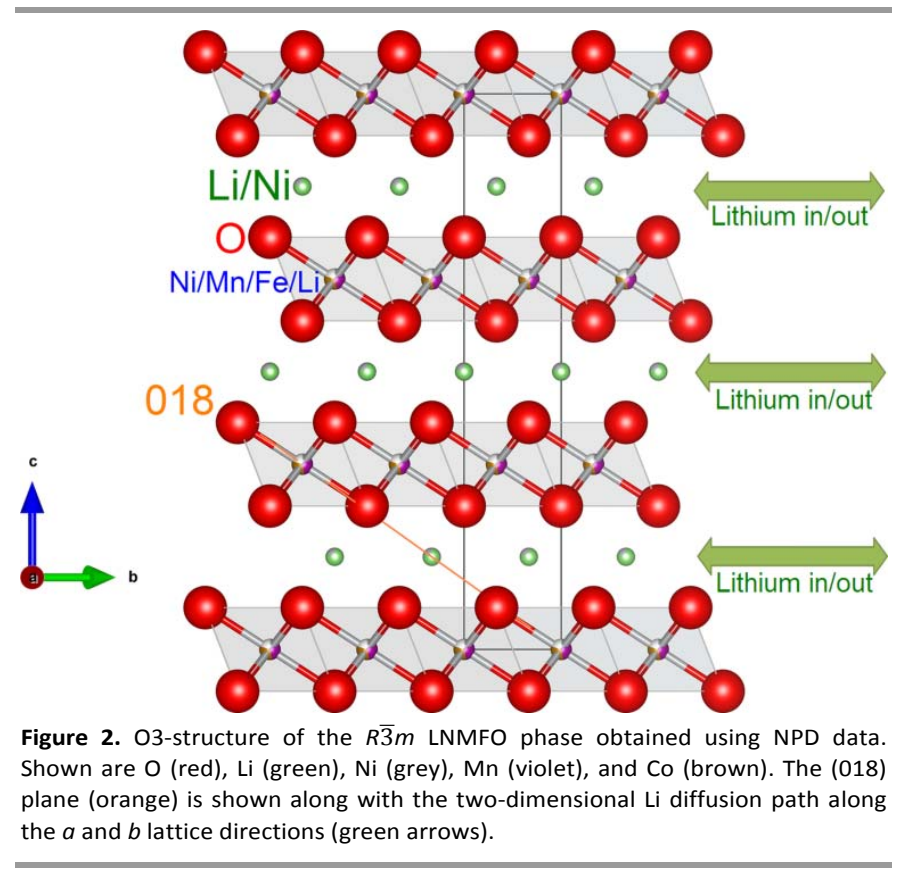

Table 1. Crystallography of the as-prepared LNMFO powder obtained using the NPD (upper) and XRPD (bottom) data.

$\left(\mathrm{Li}_{0.8} \mathrm{Ni}_{0.2}\right)\left(\mathrm{Li}_{0.2} \mathrm{Ni}_{0.13} \mathrm{Mn}_{0.33} \mathrm{Fe}_{0.33}\right) \mathrm{O}_{2}(R \overline{3} m)$ with $a=b=2.9275(3) \AA$ and $c=$ $14.344(3) \AA$

\begin{tabular}{ccccccc}
\hline Atom & Site & $\mathrm{x}$ & $\mathrm{y}$ & $\mathrm{z}$ & $\begin{array}{c}\text { Atomic displacement } \\
\text { parameter }\left(\AA^{2}\right)\end{array}$ & $\begin{array}{c}\text { Site } \\
\text { occupancy } \\
\text { factor }\end{array}$ \\
\hline Li1 & $3 b$ & 0 & 0 & 0.5 & $0.79(4)^{*}$ & $0.80(4)^{+}$ \\
$\mathrm{Ni} 1$ & $3 b$ & 0 & 0 & 0.5 & $0.79(4)^{*}$ & $0.20(4)^{+, \sim}$ \\
$\mathrm{L} 2$ & $3 a$ & 0 & 0 & 0 & $0.2(1)^{\#}$ & $0.20(4)^{\sim}$ \\
$\mathrm{N} 2$ & $3 a$ & 0 & 0 & 0 & $0.2(1)^{\#}$ & $0.13(4)^{\wedge}$ \\
$\mathrm{Mn} 2$ & $3 a$ & 0 & 0 & 0 & $0.2(1)^{\#}$ & $0.33^{\wedge}$ \\
$\mathrm{Fe} 2$ & $3 a$ & 0 & 0 & 0 & $0.2(1)^{\sharp}$ & $0.33^{\wedge}$ \\
$\mathrm{O} 1$ & $6 c$ & 0 & 0 & $0.2580(3)$ & $0.38(1)$ & 1 \\
\hline
\end{tabular}

*,\#, $\sim$ constrained to be the same.

${ }^{+}, \wedge$ constrained to add to 1 .

\begin{tabular}{|c|c|c|c|c|c|c|}
\hline \multicolumn{7}{|c|}{$\begin{array}{c}\left(\mathrm{Li}_{0.75} \mathrm{Ni}_{0.25}\right)\left(\mathrm{Li}_{0.25} \mathrm{Ni}_{0.08} \mathrm{Mn}_{0.33} \mathrm{Fe}_{0.33}\right) \mathrm{O}_{2}(R \overline{3} m) \text { with } a=b=2.9227(1) \AA \text { and } c \\
=14.3808(2) \AA\end{array}$} \\
\hline Atom & Site & $\mathrm{x}$ & $\mathrm{y}$ & $\mathrm{z}$ & $\begin{array}{l}\text { Atomic displacement } \\
\text { parameter }\left(\AA^{2}\right)\end{array}$ & $\begin{array}{c}\text { Site } \\
\text { occupancy } \\
\text { factor }\end{array}$ \\
\hline Li1 & $3 b$ & 0 & 0 & 0.5 & $0.79^{(}$ & $0.75(4)^{+}$ \\
\hline Ni1 & $3 b$ & 0 & 0 & 0.5 & $0.79^{@}$ & $0.25(4)^{+, \sim}$ \\
\hline Li2 & $3 a$ & 0 & 0 & 0 & $0.2^{\circledR}$ & $0.25(4)^{\sim}$ \\
\hline $\mathrm{Ni} 2$ & $3 a$ & 0 & 0 & 0 & $0.2^{\circledR}$ & $0.08(4)^{\wedge}$ \\
\hline Mn2 & $3 a$ & 0 & 0 & 0 & $0.2^{@}$ & $0.33^{\prime}$ \\
\hline $\mathrm{Fe} 2$ & $3 a$ & 0 & 0 & 0 & $0.2^{\circledR}$ & $0.33^{\wedge}$ \\
\hline O1 & $6 c$ & 0 & 0 & $0.2551(3)$ & $0.38^{@}$ & 1 \\
\hline
\end{tabular}

${ }^{\circledR}$ taken from refinement results using the NPD data.

constrained to be the same.

${ }^{+}, \wedge$ constrained to add to 1 .

To correlate the electrochemical performance with the structural evolution of the cathode, high-intensity NPD data of a neutron-friendly battery containing this cathode during charge and discharge were collected. These data are complicated by the same peak broadening affecting the high-resolution NPD data, but also from additional peaks and features in the data from the other components of the battery. Such features include a significant background from the hydrogen-containing separator and scattering from the liquid electrolyte, and reflections overlapping those of the cathode arising from the aluminum pouch. Detailed structural analysis of the cathode was therefore limited. A Rietveld refinement plot using the NPD data of the battery prior to electrochemical cycling is shown in Figure 3. 


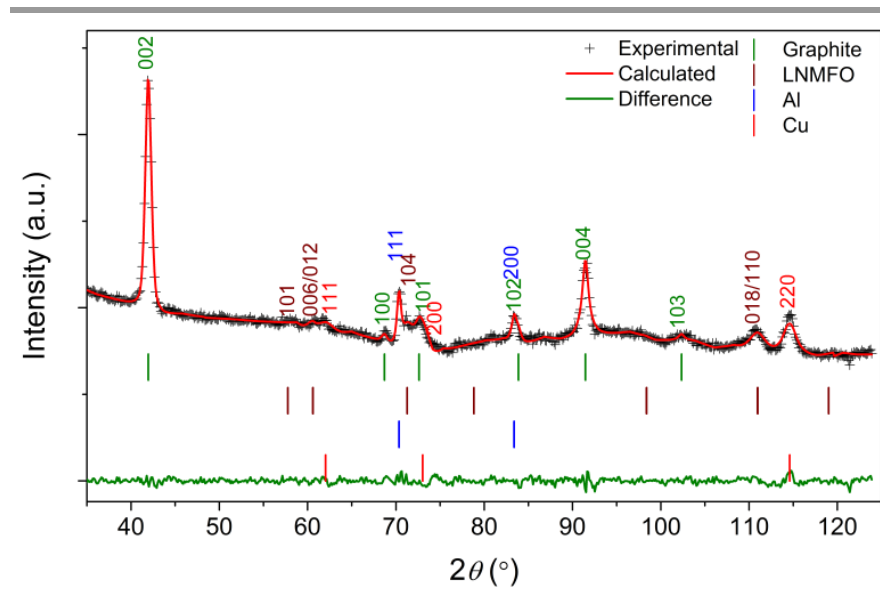

Figure 3. Refinement plot using the NPD data of the LNMFO-containing battery before cycling. Figures-of-merit include $\chi^{2}=2.53$, Rwp $=13.3 \%$, with Bragg-R factors $1.05 \%$ for LNMFO, $0.17 \%$ for graphite, $0.42 \%$ for $\mathrm{Cu}$, and $0.28 \%$ for Al.

There are, as expected, four identifiable phases in the asprepared battery, these being $\mathrm{Al}$, graphite, $\mathrm{Cu}$, and LNMFO. The second Li-rich phase of the cathode was not observed as a result of the significant background. The strongest LNMFO reflections in the high-resolution NPD data, the 006/012, 104, and 018/110 reflections, are identified in these high-intensity NPD data, although these are weak. During charging, these LNMFO reflections become less intense and are nearly unobservable at the charged state of the battery. Consequently, standard sequential Rietveld-refinement using the operando NPD data was difficult, and possible only using a highlyconstrained model with the background and oxygen positionalparameter $(z)$ the only refineable parameters, where the anode lattice was analyzed using Le Bail extraction. Rietveld analysis was also supplemented with single-peak fitting to understand the structural changes occurring to the LNMFO phase during charge/discharge cycling.

The battery voltage during the operando experiment is shown in Figure S1. During the battery formation cycle (the first), electrolyte decomposition is observed at the battery's high charge-state (4.48 V vs. MCMB), appearing as a drop in the liquid structure-factor contribution to the pattern arising from the electrolyte (arrow in Figure S1). During the first cycle, the large irreversible-capacity of $41.2 \mathrm{mAh}$ (coulombic efficiency of $51 \%$ ) was obtained, which may be ascribed to the electrolyte decomposition and the formation of a solid-electrolyte interface. After the first cycle, efficiencies of $89.1 \%$ and $87.0 \%$ are observed during cycling at 3 and $4.5 \mathrm{~mA}$, respectively. The calculated charge (83.25 $\mathrm{mAh})$ and discharge (41.2 $\mathrm{mAh})$ capacities are equivalent to 104.1 and $52.6 \mathrm{mAh} . \mathrm{g}^{-1}$, respectively, for total composite-cathode. The use of deuterated electrolyte with a heavier molecular-mass and higher viscosity can be detrimental to battery performance, as noted in previous work. $^{42-46}$ The incremental capacity-plot (Figure 4) exhibits features only from the couples expected to be redox-active between 3 and $4.3 \mathrm{~V}$, which correspond to $\mathrm{Ni}^{2+} / \mathrm{Ni}^{3+}$ and $\mathrm{Ni}^{3+} / \mathrm{Ni}^{4+}$ transitions, respectively. ${ }^{47}$ The absence of a peak around $3 \mathrm{~V}$ indicates the $\mathrm{Mn}^{3+} / \mathrm{Mn}^{4+}$ redox couple is inactive and that no or minor amounts of $\mathrm{Mn}^{3+}$ are present in the cathode. ${ }^{48}$ The presence of electrochemically-inactive $\mathrm{Mn}^{4+}$ is expected to impart structural stability to the cathode, which alongside $\mathrm{Fe}^{3+}$, also not electrochemically active in the voltage range proposed for this cathode, promote structural stability. ${ }^{8}$

\begin{tabular}{lcc}
\hline \multicolumn{3}{l}{ Table 2. Ni-O bond lengths at various Ni valences. } \\
\hline \multicolumn{3}{c}{$\begin{array}{c}\text { Reported Ni-O bond } \\
\text { length }\end{array}$} \\
& 1.675 & Reference \\
\hline $\mathrm{Ni}^{2+}$ & 1.750 & Brown and Altermatt, (1985) \\
$\mathrm{Ni}^{3+}$ & 1.780 & I.D.Brown Private communication \\
$\mathrm{Ni}^{4+}$ & & I.D.Brown Private communication \\
\hline
\end{tabular}

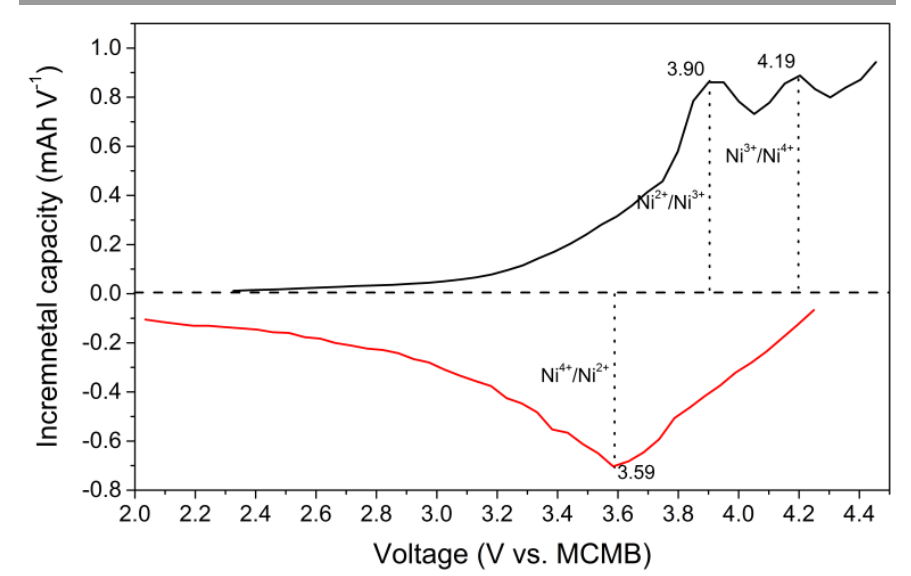

Figure 4. Incremental capacity-plot for the LMNFO-containing battery during the second cycle, identifying key voltages in the battery mechanism, where the black and red curves represent charge and discharge, respectively.

To understand the battery function in terms of structure, we first examine the graphite 002 reflection of the anode $\left(\sim 42.0^{\circ}\right.$ in $2 \theta$ ) in the operando NPD data for the battery (Figure S1). The shift in position of the graphite 002 reflection arises from lithiation and delithiation, with the observed phase transformation agreeing well with the battery voltage-curve. Given that the anode is in excess in the battery to ensure the complete reaction of cathode, the complete lithiation of graphite to the $\mathrm{LiC}_{6}$ phase is not observed, with the $\mathrm{LiC}_{6} 001$ reflection $(d \sim 3.70 \AA)^{50}$ expected at $\sim 38.0^{\circ}$ in $2 \theta$, not appearing. Fitting of the overlapping lithiated graphite reflections with Gaussian functions reveals peak positions corresponding to that of $\mathrm{C}, \mathrm{LiC}_{18}$, and $\mathrm{LiC}_{12}$ (Figure S2 and S3) ${ }^{50}$ Based on the evolution of intensity of these peaks during charge/discharge, we note the presence of the two-phase C$\mathrm{LiC}_{18}$ and $\mathrm{LiC}_{18}-\mathrm{LiC}_{12}$ reactions that confirm the expected reversible lithiation of the anode.

Gaussian peak-fitting of the LNMFO reflections in the operando NPD data is complicated by significant peak overlap. The contour plot of the operando data (see Figure S4 in the supporting information) reveals that the 006/012 reflections change during delithiation and lithiation. Figure 5a shows the evolution of the $2 \theta$ position of the LNMFO 006/012 reflections obtained through single Gaussian peak-fitting during charge/discharge cycling. Given the reported structural response of the $R \overline{3} m \mathrm{LiCoO}_{2}{ }^{2-4}$ and $\mathrm{Li}\left(\mathrm{Ni}_{1 / 3} \mathrm{Mn}_{1 / 3} \mathrm{Co}_{1 / 3}\right) \mathrm{O}_{2}{ }^{18,} 29$ 
during lithiation and delithiation, iso-structural to LNMFO, we expect the lattice parameter $c$ for LNMFO to first increase and then decrease during the battery charging. This non-Vegard change of the lattice parameter $c$ in the hexagonal-layered cathodes is ascribed to electrostatic repulsion between the Ocontaining layers and the subsequent deficient average-charge of the $\mathrm{O}$ ions (Figure 2). Interestingly, no inflection point is observed in the position of the overlapping LNMFO 006/012 reflections (Figure 5a), with the peak shifting to higher and lower angle during charge and discharge, respectively. Given the hexagonal-layered structure of the LNMFO and known lattice response of iso-structural cathodes during lithiation/delithiation, ${ }^{2,} 29$ the change in the position of the LNMFO 006/012 reflections is likely dominated by that of the $c$ axis change as a result of changing $\mathrm{Li}$ content. ${ }^{51,} 52$ The substitution of $\mathrm{Co}$ by $\mathrm{Fe}$ is not expected to alter the electrochemistry of a $R \overline{3} m$ ternary cathode, and the dissimilar lattice evolution of the LNMFO and other iso-structural cathodes must therefore be attributed to the high level of $\mathrm{Li} / \mathrm{Ni}$ cation mixing in LNMFO.

Given the $\sim 25 \%$ inert $\mathrm{Li}_{2} M \mathrm{O}_{3}$ phase and the specific charge capacity of $104.1 \mathrm{mAh} . \mathrm{g}^{-1}$ for the composite cathode during the first charge in the operando NPD experiment, we calculate a capacity of $\sim 139 \mathrm{mAh} . \mathrm{g}^{-1}$ for the active LNMFO phase, which we note closely approaches that of $\left.\mathrm{LiCoO}_{2}\left(\sim 140 \mathrm{mAh} \cdot \mathrm{g}^{-1}\right)\right)^{2-4}$ For relatively equal capacity, the LNMFO exhibits a significantly smaller $(\sim 80 \%)$ change along the $[00 l]$ direction during charge/discharge compared with the $\mathrm{LiCoO}_{2}{ }^{2-4}$, with the peak position of the LNMFO 006/012 reflections shifting by only $0.8 \%$ compared with $\sim 4.0 \%$ for the $\mathrm{LiCoO}_{2} 006$ reflection). ${ }^{2-4}$

The LNMFO 018 and 110 reflections also overlap, and the evolution of the peak intensity of the Gaussian peak describing these is shown in Figure 5b. The contour plot of the operando data (see Figure S5 in the supporting information) reveals that the 018 and 110 reflections separate somewhat and their intensity decreases during delithiation, with the reverse occurring during lithiation. As the LNMFO 018 and 110 reflections are broad and the inter-planar spacing of these is close, single-peak fitting is used to monitor the changes of the two reflections. The LNMFO (018) and (110) planes consist of all the elements in the material $(\mathrm{Li}, \mathrm{Fe}, \mathrm{Mn}, \mathrm{Ni}$, and $\mathrm{O}$, Figure 2). Considering that $\mathrm{Li}$ and $\mathrm{Mn}$ have negative coherent neutronscattering lengths (-1.9 and $-3.7 \mathrm{fm}$, respectively) and that $\mathrm{Fe}$, $\mathrm{Ni}$, and $\mathrm{O}$ have positive coherent neutron-scattering lengths (9.5, 10.3, and $5.8 \mathrm{fm}$, respectively), if only the population of the active Li site $(3 b)$ during charge/discharge is considered, then the intensity of the LNMFO $018 / 110$ reflections is expected to increase and decrease during $\mathrm{Li} 3 b$ site depopulation and population, respectively. We observe the opposite here, with the changes in the intensity of the LNMFO $018 / 110$ reflections driven by changes in the oxygen positionalparameter. During lithiation/delithiation (reduction/oxidation), the transition-metal to oxygen bond-length changes as a result of the valence change of the redox center. Our incremental capacity-plot (Figure 4) indicates that the $\mathrm{Ni}^{2+} / \mathrm{Ni}^{3+} / \mathrm{Ni}^{4+}$ is the active redox center in the LNMFO and therefore responsible for the average-valence change of the octahedral metal-sites. Table 2 summarizes the reported length of the Ni-O bond at various $\mathrm{Ni}$ oxidation states obtained from bond-valence summation calculations. ${ }^{49}$ The Ni-O bond in similar materials is longest at higher oxidation-states of $\mathrm{Ni}$, contrary to that expected from a simple electrostatic argument.
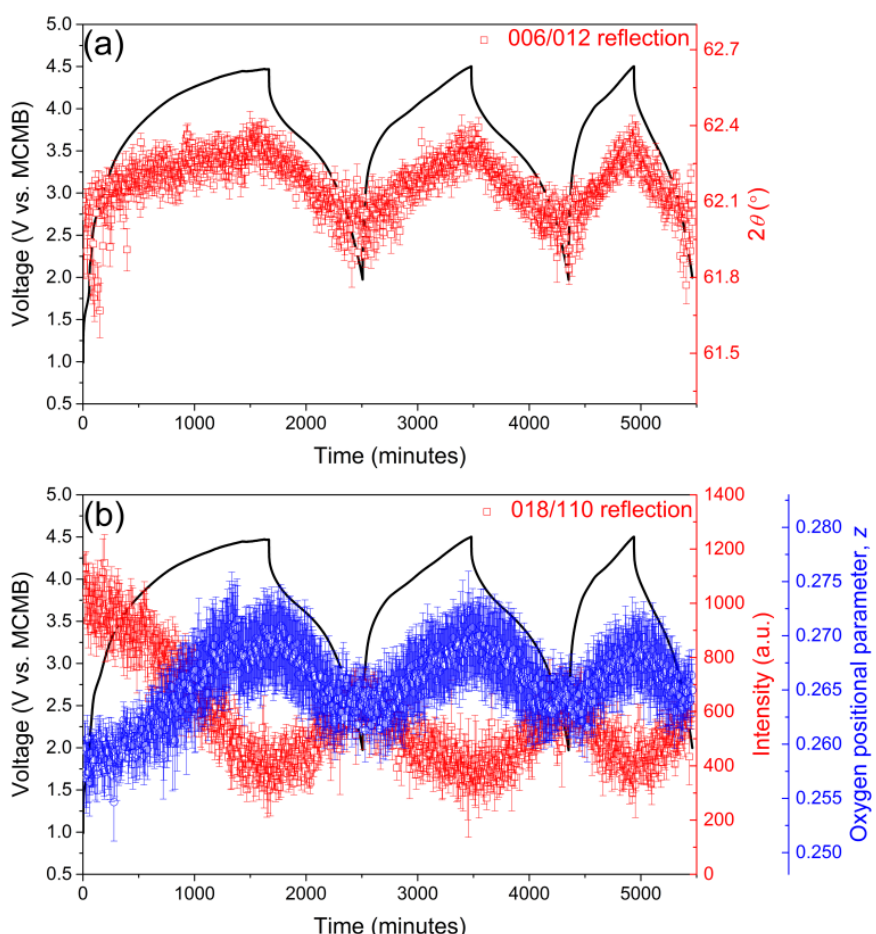

Figure 5. (a) Evolution of the $2 \vartheta$ position of the Gaussian peak describing the LNMFO 006/012 reflections and (b) the evolution of intensity of the Gaussian peak describing the LNMFO 018/110 reflections, associated with the refined $z$, during charge/discharge cycling (see Figure S3 and S1 in the supporting information).

To understand further the structural response of the LNMFO during charge/discharge, the oxygen positional-parameter $(z)$ was extracted using highly-constrained Rietveld refinement, and $z$ is shown alongside the intensity change of the LNMFO $018 / 110$ peak in Figure $5 \mathrm{~b}$. The decrease and increase in $018 / 110$ peak intensity are associated with the increase and decrease, respectively, of $z$. To further support this finding, simulated NPD patterns of LNMFO with various $z$ were created and the relative $018 / 110$ peak intensity compared with that experimentally-obtained (Figure S6). The simulated NPD patterns for LNMFO with different $z$ were calculated using the refined structure obtained from the high-resolution NPD data and with the same lattice parameter and atomic site-occupancy factors, despite these being known to vary alongside changes in $z$ in iso-structural cathodes. The LNMFO 018/110 reflections in simulated patterns were fitted using a Gaussian function to examine the trend of intensity variation as a function of oxygen positional-parameter. This is shown alongside the measured intensity using NPD and the refined $z$ in Figure 6, which expectedly show significant scatter due to the relatively-large 
error associated with the highly-constrained refinement (error bars are omitted for clarity). The trends of the experimentallyobtained and simulated-intensity variation with $z$ are in agreement, and we correlate the experimentally-obtained battery state-of-charge with the calculated $z$ to explore the $M$-O bond distance as a function of battery charge-state.

Within the $z$ range $0.25-0.27$, the variation of the $2 \theta$ position of the $018 / 110$ reflections is small and the significant linear decrease in reflection intensity is associated with the movement of oxygen away from the redox center (increasing $z$, Figure 6). This result indicates a lengthening of the $M$-O bond during delithiation, which is behaviour consistent with that of the isostructural $\mathrm{Li}\left(\mathrm{Ni}_{1 / 3} \mathrm{Mn}_{1 / 3} \mathrm{Co}_{1 / 3}\right) \mathrm{O}_{2}$ material. ${ }^{18} \mathrm{~A}$ consideration of the Ni-O bond length at various $\mathrm{Ni}$ oxidation states (Table 2) reveals activity of the $\mathrm{Ni}^{2+} / \mathrm{Ni}^{3+} / \mathrm{Ni}^{4+}$ redox center.

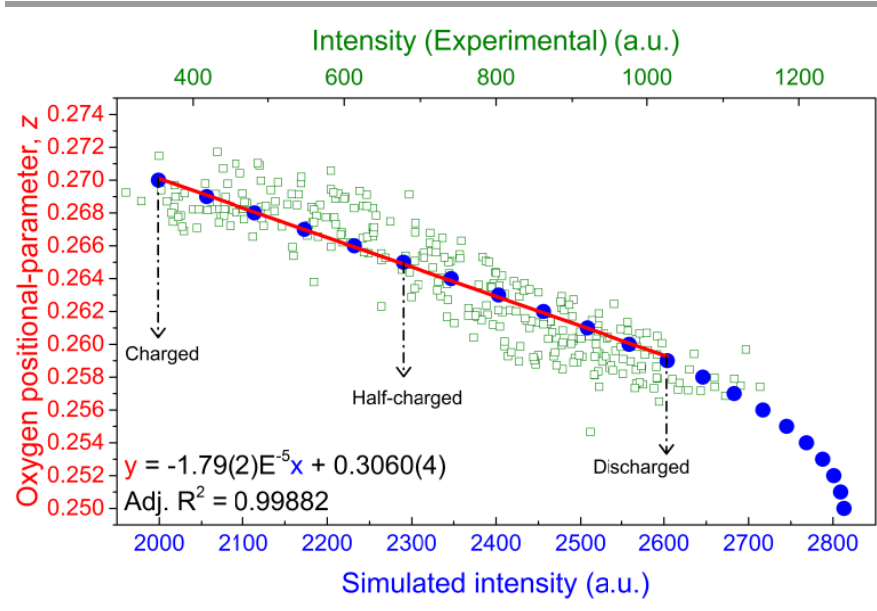

Figure 6. LNMFO $018 / 110$ reflection intensity as a function of $z$, obtained by Gaussian peak fitting, with the linear fitting shown in red. The square green rectangles are the measured intensity from experimental data and the solid blue circles are the calculated reflection intensity from the simulated data.

The structure of the transition-metal oxygen octahedron with values of $z$ associated with the measured 018/110 reflection intensity at the 0,50 , and $100 \%$ charge states of the battery $(z=$ $0.258,0.264$, and 0.270 , respectively) is shown in Figure 7. Changes in the oxygen position are associated with changing $M$-O bond length, and also with distortion of the transitionmetal oxygen octahedron, represented by the oxygen-transition metal-oxygen angle. On charging to the $50 \%$ and $100 \%$ charge state, this angle increases by $3 \%$ and $6 \%$, respectively (from $93.3^{\circ}$ to $96.1^{\circ}$ and $99.0^{\circ}$, respectively). During lithiation, the LNMFO exhibits only a minor change in lattice, a phenomenon correlated to increasing octahedral distortion which likely assists in stabilizing the LNMFO structure.

The galvanostatic charge-discharge characteristics of the cathode were measured using coin-type half-cells between 2 and $4.5 \mathrm{~V}$ (vs. Li) at a current rate of 0.1 C (Figure 8a). These results indicate that the cathode delivered an initial discharge capacity of $\sim 103 \mathrm{mAh} . \mathrm{g}^{-1}$ at $0.1 \mathrm{C}^{39,}{ }^{40} \mathrm{We}$ again note that our cathode is a composite containing $\sim 25 \%$ electrochemicallyinert $\mathrm{Li}_{2} M \mathrm{O}_{3}$, with the active LNMFO having a capacity $\sim 137$ $\mathrm{mAh} \cdot \mathrm{g}^{-1}$ that approaches that of $\mathrm{LiCoO}_{2}\left(\sim 140 \mathrm{mAh} \cdot \mathrm{g}^{-1}\right)$ and of $\mathrm{Li}\left(\mathrm{Mn}_{1 / 3} \mathrm{Ni}_{1 / 3} \mathrm{Co}_{1 / 3}\right) \mathrm{O}_{2}\left(\sim 160 \mathrm{mAh} \cdot \mathrm{g}^{-1}\right)$. We show that it is the $\mathrm{Ni}^{2+} / \mathrm{Ni}^{3+} / \mathrm{Ni}^{4+}$ redox center that contributes to the LNMFO capacity, where the $\mathrm{Fe}^{3+}$ and $\mathrm{Mn}^{4+}$ are not active in the voltage range of the battery and promote further structural stability at the expense of higher capacity. ${ }^{8}, 23$ The composite cathode retains a discharge capacity of $\sim 87 \mathrm{mAh} . \mathrm{g}^{-1}\left(116 \mathrm{mAh} \cdot \mathrm{g}^{-1}\right.$ for the LNMFO phase) after 100 cycles with no significant variation in the voltage plateaux of the charge-discharge curves, indicating $84 \%$ capacity retention and low electrodepolarization. Additionally, cells electrochemically-cycled over 100 times showed a coulombic efficiency of $\sim 99 \%$ (Figure 8b). Nyquist plots (Figure S7 in the supporting information) indicate a similar charge-transfer resistance for the cathode before and after 100 cycles $(\sim 35$ and $\sim 48 \Omega$, respectively $)$ with this implying facile ionic/electronic transfer kinetics.

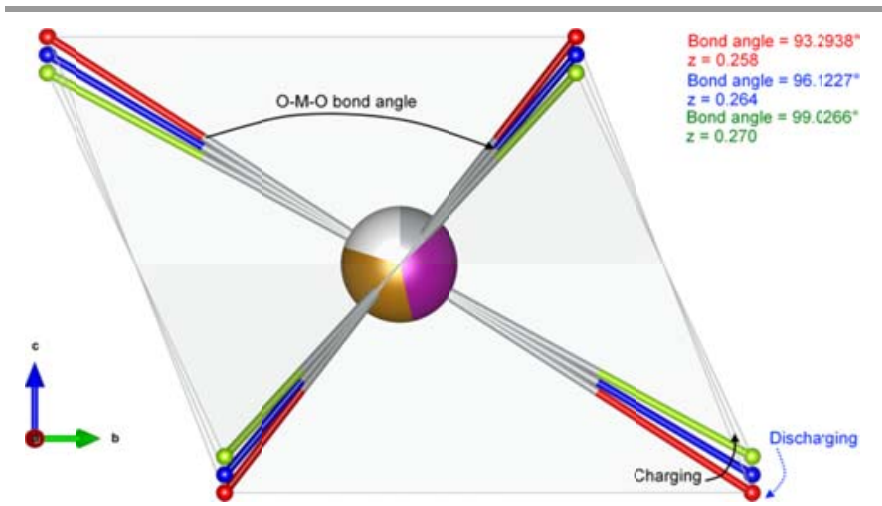

Figure 7. Calculated structure of the metal-oxygen octahedron at various oxygen positional-parameter $(z)$ values. Oxygen is shown at $z=0.258$ (red), $z=0.264$ (yellow), and $z=0.270$ (green), these corresponding to the 0,50 , and $100 \%$ battery charge-states. 

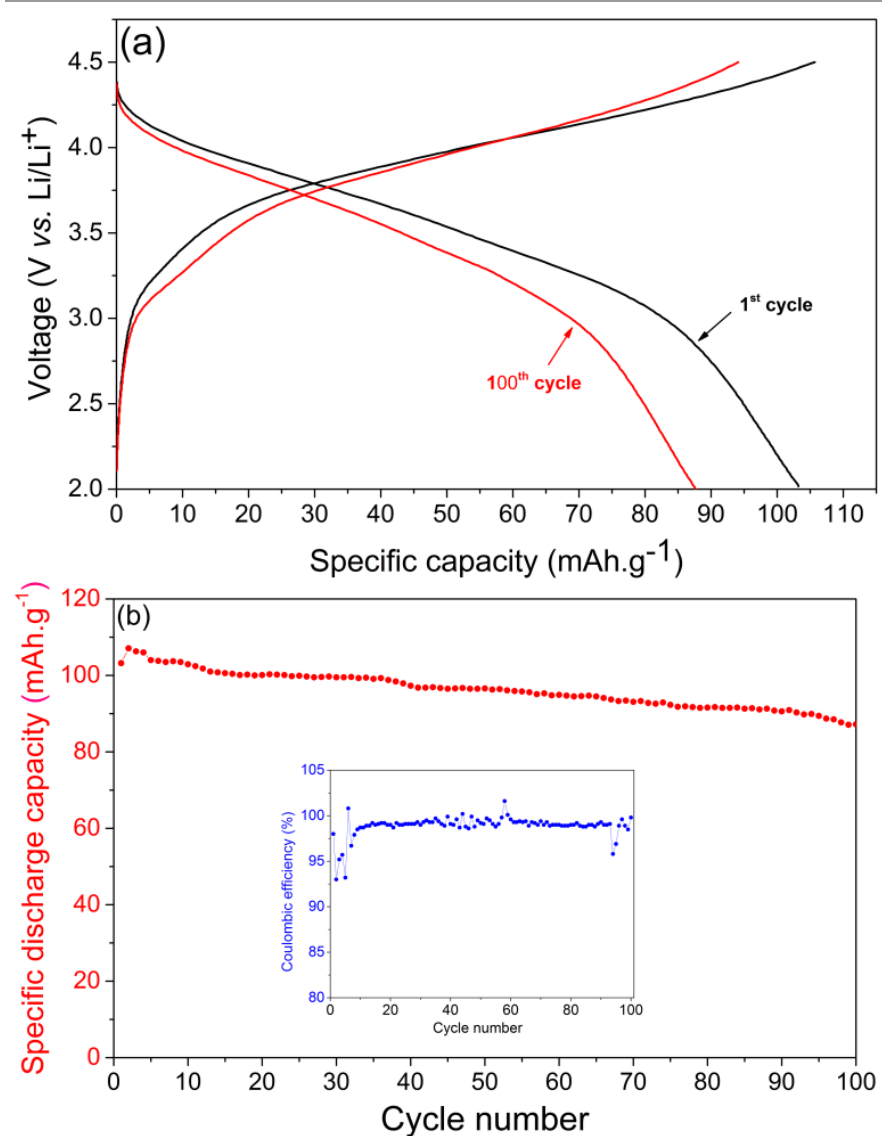

Figure 8. (a) Charge-discharge curves and (b) the variation of discharge capacity of the cathode during the $1^{\text {st }}$ and $100^{\text {th }}$ cycle at $0.1 \mathrm{C}$.

\section{Conclusions}

Nano-sized Li-rich, Co-free $\mathrm{Li}_{1+{ }_{x}} M \mathrm{O}_{2}(M=\mathrm{Li}, \mathrm{Ni}, \mathrm{Mn}, \mathrm{Fe})$ for application as a lithium-ion battery cathode was prepared using a simple and direct wet-chemical method. The as-synthesized powder was characterized and found to contain predominantly $\left(\mathrm{Li}_{0.80(4)} \mathrm{Ni}_{0.20(4)}\right)^{3 b}\left(\mathrm{Li}_{0.20(4)} \mathrm{Ni}_{0.13(4)} \mathrm{Mn}_{0.33} \mathrm{Fe}_{0.33}\right)^{3 a} \mathrm{O}_{2}$, a phase with a layered $R \overline{3} m$ structure and a high level of cation mixing, alongside a more minor $(\sim 25 \%)$ inert $\mathrm{Li}_{2} \mathrm{MO}_{3}$ secondary phase. The performance characteristics of the Co-free cathode approach that of commercial and Co-containing counterparts, before optimization. We studied the structural evolution of the active $\left(\mathrm{Li}_{0.80(4)} \mathrm{Ni}_{0.20(4)}\right)\left(\mathrm{Li}_{0.20(4)} \mathrm{Ni}_{0.13(4)} \mathrm{Mn}_{0.33} \mathrm{Fe}_{0.33}\right) \mathrm{O}_{2}$ phase using operando neutron powder-diffraction and found a lattice response that was dissimilar to iso-structural cathodes, attributable to the different level of cation mixing. We show that the capacity of this novel material comes from the $\mathrm{Ni}^{2+} / \mathrm{Ni}^{3+} / \mathrm{Ni}^{4+}$ redox centers. Notably, the operando powderdiffraction results suggest excellent structural-stability of the active component, which exhibits a change of only $\sim 0.8 \%$ (for $\sim 139 \mathrm{mAh} . \mathrm{g}^{-1}$ ) of the stacking axis of its layered structure, compared with the $\sim 4 \%$ change in $\mathrm{LiCoO}_{2}$ (for $\sim 140 \mathrm{mAh} \cdot \mathrm{g}^{-1}$ ), a characteristic that may be exploited to enhance capacity retention of this and similar materials.

\section{Acknowledgements}

The authors would like to thank the staff members at the Bragg Institute, ANSTO for their operations support. Authors also would like to acknowledge part of work supported by Automotive CRC2020 and Electron Microscopy Center of University of Wollongong.

\section{Notes and references}

${ }^{a}$ Australian Nuclear Science and Technology Organization, Locked Bag 2001, Kirrawee DC, NSW 2232, Australia.

${ }^{b}$ School of Mechanical, Materials, and Mechatronic Engineering, Institute for Superconducting \& Electronic Materials, Faculty of Engineering, University of Wollongong, NSW 2522, Australia. Electronic Supplementary Information (ESI) available: Intensity contour plot of graphite 002 reflection, alongside with the charge-discharge curves of the battery during operando neutron powder diffraction experiment (Figure S1); Operando NPD anode reflections corresponding to the lithiation and delithiation of graphite (Figure S2) and the Gaussianpeak fitting (Figure S3); Intensity contour plot of NPD data of the cathode 006/012 (Figure S4) reflections and 018 reflections (Figure S5); Simulated NPD patterns of LNMFO with various oxygen positional parameter (z) (Figure S6); and AC-impendence (Nyquist) plot of a LNMFO-containing coin-cell before and after 100 cycles (Figure S7) are provided. See DOI: 10.1039/b000000x/

\section{References}

1. Y. Nishi, J. Power Sources, 2001, 100, 101-106.

2. G. G. Amatucci, J. M. Tarascon and L. C. Klein, J. Electrochem. Soc., 1996, 143, 1114-1123.

3. A. Van der Ven, M. K. Aydinol, G. Ceder, G. Kresse and J. Hafner, Phys. Rev. B, 1998, 58, 2975-2987.

4. S. Laubach, S. Laubach, P. C. Schmidt, D. Ensling, S. Schmid, W. Jaegermann, Thi, K. Nikolowski and H. Ehrenberg, Phys. Chem. Chem. Phys., 2009, 11, 3278-3289.

5. T. Ohzuku, A. Ueda and M. Nagayama, J. Electrochem. Soc., 1993, 140, 1862-1870.

6. L. Croguennec, P. Deniard, R. Brec and A. Lecerf, J. Mater. Chem., 1995, 5, 1919-1925.

7. T. Ohzuku, A. Ueda and T. Hirai, Chem. Express, 1992, 7, 193-196.

8. M. Tabuchi, Y. Nabeshima, T. Takeuchi, H. Kageyama, K. Tatsumi, J. Akimoto, H. Shibuya and J. Imaizumi, J. Power Sources, 2011, 196, 3611-3622.

9. M. Tabuchi, A. Nakashima, H. Shigemura, K. Ado, H. Kobayashi, H. Sakaebe, H. Kageyama, T. Nakamura, M. Kohzaki, A. Hirano and R. Kanno, J. Electrochem. Soc., 2002, 149, A509-A524.

10. R. Wang, X. He, L. He, F. Wang, R. Xiao, L. Gu, H. Li and L. Chen, Adv. Energy Mater., 2013, 3, 1358-1367.

11. W. K. Pang, J. Y. Lee, Y. S. Wei and S. H. Wu, Mater. Chem. Phys., 2013, 139, 241-246.

12. G. Ceder and S. K. Mishra, Electrochem. Solid-State Lett., 1999, 2, 550-552.

13. D. Wang, L. M. Liu, S. J. Zhao, B. H. Li, H. Liu and X. F. Lang, Phys. Chem. Chem. Phys., 2013, 15, 9075-9083. 
14. M. Ecker, N. Nieto, S. Käbitz, J. Schmalstieg, H. Blanke, A. Warnecke and D. U. Sauer, J. Power Sources, 2014, 248, 839851.

15. J. Schmalstieg, S. Käbitz, M. Ecker and D. U. Sauer, J. Power Sources, 2014, 257, 325-334.

16. N. Yabuuchi and T. Ohzuku, J. Power Sources, 2003, 119-121, 171174.

17. K. M. Shaju and P. G. Bruce, Adv. Mater., 2006, 18, 2330-2334.

18. S. C. Yin, Y. H. Rho, I. Swainson and L. F. Nazar, Chem. Mater., 2006, 18, 1901-1910.

19. S. J. Shi, Y. J. Mai, Y. Y. Tang, C. D. Gu, X. L. Wang and J. P. Tu, Electrochim. Acta, 2012, 77, 39-46.

20. H.-S. Kim, K.-T. Kim and P. Periasamy, Electronic Mater. Lett., 2006, 2, 119-126.

21. H. Yu, Y. Qian, M. Otani, D. Tang, S. Guo, Y. Zhu and H. Zhou, Energy Environ. Sci., 2014, 7, 1068-1078.

22. A. Boulineau, L. Croguennec, C. Delmas and F. Weill, Chem. Mater., 2009, 21, 4216-4222.

23. C. S. Johnson, J. S. Kim, C. Lefief, N. Li, J. T. Vaughey and M. M. Thackeray, Electrochem. Comm., 2004, 6, 1085-1091.

24. J. Liu, M. Hou, J. Yi, S. Guo, C. Wang and Y. Xia, Energy Environ. Sci., 2014, 7, 705-714.

25. M. M. Thackeray, C. Wolverton and E. D. Isaacs, Energy Environ. Sci., 2012, 5, 7854-7863.

26. J.-S. Kim, C. S. Johnson, J. T. Vaughey, M. M. Thackeray, S. A. Hackney, W. Yoon and C. P. Grey, Chem. Mater., 2004, 16, 1996-2006.

27. C. S. Johnson, N. Li, C. Lefief, J. T. Vaughey and M. M. Thackeray, Chem. Mater., 2008, 20, 6095-6106.

28. P. Kalyani, S. Chitra, T. Mohan and S. Gopukumar, J. Power Sources, 1999, 80, 103-106.

29. O. Dolotko, A. Senyshyn, M. J. Mühlbauer, K. Nikolowski and H. Ehrenberg, J. Power Sources, 2014, 255, 197-203.

30. X. Zhang, W. J. Jiang, A. Mauger, Qilu, F. Gendron and C. M. Julien, J. Power Sources, 2010, 195, 1292-1301.

31. L. Baggetto, D. Mohanty, R. A. Meisner, C. A. Bridges, C. Daniel, D. L. Wood Iii, N. J. Dudney and G. M. Veith, RSC Advances, 2014, 4, 23364-23371.

32. C. M. Julien, A. Mauger, K. Zaghib and H. Groult, Inorganics, 2014, 2, 132-154.

33. B. Xu, D. Qian, Z. Wang and Y. S. Meng, Mater. Sci. Eng. R, 2012, 73, 51-65.

34. K.-D. Liss, B. Hunter, M. Hagen, T. Noakes and S. Kennedy, Physica B, 2006, 385-386, Part 2, 1010-1012.

35. J. Rodríguez-Carvajal, Physica B, 1993, 192, 55-69.

36. T. Roisnel and J. Rodriguez-Carvajal, 2000.

37. A. J. Studer, M. E. Hagen and T. J. Noakes, Physica B, 2006, 385386, Part 2, 1013-1015.

38. D. Richard, M. Ferrand and G. J. Kearley, J. Neutron Res., 1996, 4, 33-39.

39. K. Karthikeyan, S. Amaresh, G. W. Lee, V. Aravindan, H. Kim, K. S. Kang, W. S. Kim and Y. S. Lee, Electrochim. Acta, 2012, 68, 246-253.

40. K. Karthikeyan, S. Amaresh, V. Aravindan, W. S. Kim, K. W. Nam, X. Q. Yang and Y. S. Lee, J. Power Sources, 2013, 232, 240245 .
41. Y.-J. Shin, W.-J. Choi, Y.-S. Hong, S. Yoon, K. S. Ryu and S. H. Chang, Solid State Ionics, 2006, 177, 515-521.

42. G. Du, N. Sharma, V. K. Peterson, J. A. Kimpton, D. Jia and Z. Guo, Adv. Funct. Mater., 2011, 21, 3990-3997.

43. N. Sharma, G. Du, A. J. Studer, Z. Guo and V. K. Peterson, Solid State Ionics, 2011, 199-200, 37-43.

44. W. K. Pang, N. Sharma, V. K. Peterson, J.-J. Shiu and S.-H. Wu, J. Power Sources, 2014, 246, 464-472.

45. W. K. Pang, V. K. Peterson, N. Sharma, J.-J. Shiu and S.-h. Wu, Chem. Mater., 2014, 26, 2318-2326.

46. N. Sharma, D. Yu, Y. Zhu, Y. Wu and V. K. Peterson, Chem. Mater, 2013, 25, 754-760.

47. K. M. Shaju, G. V. Subba Rao and B. V. R. Chowdari, Electrochim. Acta, 2002, 48, 145-151.

48. C. Gan, X. Hu, H. Zhan and Y. Zhou, Solid State Ionics, 2005, 176, 687-692.

49. I. D. Brown and D. Altermatt, Acta Crystallogr. Sect. B, 1985, 41, 244-247.

50. X.-L. Wang, K. An, L. Cai, Z. Feng, S. E. Nagler, C. Daniel, K. J. Rhodes, A. D. Stoica, H. D. Skorpenske, C. Liang, W. Zhang, J. Kim, Y. Qi and S. J. Harris, Sci. Rep., 2012, 2.

51. L. Vegard, Z. Physik, 1921, 5, 17-26.

52. A. R. Denton and N. W. Ashcroft, Phys. Rev. A, 1991, 43, 31613164. 